\title{
Operaciones balleneras tradicionales en las costas sudamericanas: características, transformaciones y continuidades
}

\section{Traditional whaling operations on the South American Shores: characteristics, transformations and continuities}

\author{
Daniel Quiroz ${ }^{1}$ https://orcid.org/0000-0001-7436-6142 \\ ${ }^{1}$ Servicio Nacional del Patrimonio Cultural, Subdirección de Investigación, Santiago, CHILE. \\ Email: daniel.quiroz@patrimoniocultural.gob.cl
}

\section{Resumen}

Los historiadores distinguen dos grandes categorías en la caza comercial de ballenas, cada una con un régimen tecnológico particular y específico: la caza tradicional y la caza moderna. La caza tradicional está definida por el uso de veleros, botes abiertos, arpones y lanzas manuales y la caza moderna por la presencia de buques cazadores armados con un cañón arponero explosivo montado en su proa. En la caza tradicional se distinguen dos variedades, "vasca" y "yanqui", que llegan en distintas épocas, instalándose sobre conocimientos y prácticas prexistentes en las comunidades costeras locales sudamericanas. La presencia de balleneros foráneos permite explicar el surgimiento de operaciones locales en Brasil, Argentina/Uruguay, Chile y Perú que, integrando exitosamente elementos tecnológicos, sociales y productivos de los grupos visitantes con los propios, configuran, en un juego de transformaciones y continuidades, lo que llamamos "tradiciones balleneras locales". Las operaciones balleneras tradicionales atlánticas y pacíficas muestran similitudes tecnológicas pero algunas diferencias organizacionales, sobre todo en lo que se refiere a la relevancia de iniciativa privada y al rol del Estado. Se ha comprobado que las operaciones balleneras forman parte de un emprendimiento global y en el futuro será imprescindible comprender dichas vinculaciones.

Palabras claves: caza tradicional de ballenas, tradición vasca, tradición yanqui, operaciones balleneras sudamericanas.

\begin{abstract}
Historians distinguish two major categories in commercial whaling, with a technological regime specific: traditional and modern whaling. The use of vessels, open boats, manual harpoons and spears defines traditional whaling, and modern whaling by the presence of whale catchers armed with an explosive harpoon gun mounted on its bow. In traditional whaling, two varieties, "Basque" and "Yankee", which come in South America at different times, operates on pre-existing knowledge and practices in the local coastal communities. The presence of foreign whalers makes it possible to explain the emergence of local operations in Brazil, Chile and Peru, which successfully integrates technological, social and productive elements of the visiting groups with their own in a complex set of transformations and continuities, constituting "local whaling traditions". Traditional Atlantic and Pacific whaling operations show a lot of technological similarities but some organizational differences, especially in terms of the relevance of private initiative and the role of the State. It has been proven that whaling operations are part of a global enterprise and will be essential to understand these links in the near future.
\end{abstract}

Keywords: traditional whaling, basque tradition, yankee tradition, South American whaling operations.

Recibido: 21 julio 2017. Aceptado: 3 agosto 2018 


\section{Introducción}

Los historiadores distinguen dos grandes categorías en la caza comercial de ballenas, la caza tradicional (Ellis, 2009) y la caza moderna (Clapham y Baker, 2009), cada una con un régimen tecnológico particular y específico. La caza moderna usa dispositivos técnicos "revolucionarios", el arpón explosivo y el buque con motor, que "cambiaron radicalmente la industria y permitieron la persecución y captura de cualquier especie de ballena”; además, el compresor de aire hace una diferencia pues, al introducir aire en las carcasas, se aseguraba que las ballenas no se hundieran, "reduciendo las tasas de pérdida de ejemplares" (Clapham y Baker, 2009, p. 1240). Otras innovaciones posteriores, como la rampa en los buques factoría que permitía subir el cetáceo entero para su procesamiento a bordo, harían mucho más "eficiente" las operaciones balleneras en el mundo (Basberg, 1998). Todas las formas de cazar ballenas previas a la introducción de estos dispositivos se consideran como tradicionales.

La caza comercial de ballenas se inicia en el mundo occidental a partir del siglo X o XI de nuestra era, cuando pescadores vascos capturan ballenas en las costas del golfo de Vizcaya, usando botes abiertos o chalupas y arpones de mano. La ballena era remolcada a la playa y faenada en instalaciones costeras, donde obtenían la grasa o saín que se comercializaba por toda Europa (Aguilar, 1986). Los vascos habrían aprendido sus técnicas balleneras de los normandos, quienes a su vez las habrían obtenido de los vikingos de Noruega e Islandia, que las cazaban "sin fines comerciales" (Du Pasquier, 2000). En el siglo XIV los balleneros vascos llegan a Inglaterra e Irlanda, luego a Terranova y Labrador en el XVI (Proulx, 1986) y a Brasil, Islandia y Spitsbergen en el XVII (Hacquebord, 2010). Entre los siglos XVII y XVIII, holandeses, ingleses, franceses, daneses, rusos y alemanes cazarán ballenas por todo el Atlántico Norte, contando con especialistas vascos en sus viajes, lo que permitía continuar la tradición iniciada por los vizcaínos. Los balleneros anclaban sus naves cerca de la costa y construían una estación terrestre con materiales provenientes del barco. Las ballenas eran avistadas desde la playa y luego perseguidas y cazadas con arpones de mano desde la proa de una chalupa. La carcasa de la ballena era remolcada a una estación costera donde la grasa era removida y derretida. El aceite se almacenaba en barriles de madera y transportado donde fuese necesario (Hacquebord, 2003; Schokkenbroek, 2008). El Atlántico Norte fue el dominio o espacio donde esta tradición ballenera fue desarrollada y practicada, con algunas incursiones hacia el sur.

En las costas de Nueva Inglaterra comienza la caza costera de ballenas francas enlosiniciosdelsigloXVII para obtener aceiteybarbas de ballena. Esta tradición se originaría en el contacto de los recién llegados pobladores europeos con los grupos originarios de dichas costas (Shoemaker, 2014). Los hombres de Nantucket descubren en 1720 los patrones migratorios de los cachalotes y su persecución dará origen a la caza pelágica estadounidense (Dolin, 2007). Los buques llegaron primero a "los bancos" de Brasil, luego a las islas Malvinas y recién en 1787 doblaron el cabo de Hornos e ingresaron al océano Pacífico (Pereira Salas, 1971). En 1790 se encontraban trabajando intensamente a lo largo de las costas de Chile y Perú y poco tiempo después, en todo el Pacífico Sur. La caza se realizaba en veleros que llevaban a bordo botes balleneros. Se cazaba ballenas francas y jorobadas, pero principalmente cachalotes. Cuando se divisaba una ballena, los botes eran bajados de los buques. Desde el bote el arponero lanzaba, desde muy corta distancia, uno o más arpones contra la ballena. Herida, remolcaba los botes balleneros en su huida. Cuando se cansaba era muerta por el timonel con una lanza que le hundía en el cuerpo. Luego era llevada a un costado del velero, donde era descuartizada, la grasa retirada y subida a bordo mediante poleas. En el velero era transformada en aceite usando hornos instalados a bordo. El aceite se almacenaba en barriles. Con este sistema se mejoraba la calidad del aceite y las expediciones duraban en promedio entre tres y cuatro años (Davis, Gallman y Gleiter, 1997, p. 36). La primera mitad del siglo XIX es el período de mayor auge de la industria ballenera mundial cuando numerosos veleros de distintas nacionalidades -norteamericanos, ingleses, franceses y alemanes- recorren los diversos mares del planeta en busca de las codiciadas ballenas, tocando las costas de Chile en Ancud, Talcahuano, Valparaíso y Coquimbo (Pereira Salas, 1971). La caza de ballenas se globaliza, pues se practica en casi todos los mares abiertos del planeta (Dolin, 2007). 
La caza moderna de ballenas surge en el norte de Noruega en la segunda mitad del siglo XIX, cuando se "inventa" el cañón arponero montado en buques a vapor, construidos especialmente para hacer más eficiente la cacería. El buque debía ser "rápido, poderoso, maniobrable y virtualmente imposible de hundirse" y usaba "un arpón explosivo lanzado desde un cañón montado en la proa" (Brown, 1976, p. 25). Estas innovaciones permitieron capturar todo tipo de ballenas, incluidos grandes rorcuales como la ballena azul y la de aleta, e iniciar la explotación de los mares antárticos (Tønnesen y Johnsen, 1982, pp. 39-40). Las carcasas eran procesadas en plantas terrestres y en buques factoría para producir aceite y abono. En las plantas terrestres el proceso comenzaba con la llegada de la ballena, que luego de ser izada a la rampa era llevada a la plataforma de descuartizamiento, donde se separaba el tocino, la carne y los huesos que iban a las "cocinerías". Se obtenía un aceite que era enviado a plantas de purificación y el resto, una mezcla de líquidos y sólidos, a la planta de harina o de guano (Basberg, 2004, pp. 83-84). Los buques factoría eran considerados como verdaderas "fábricas en movimiento". Los primeros buques factoría solo permitían que se trabajara al costado de la nave, cortando el tocino en grandes trozos que luego eran subidos a bordo, picados en trozos más pequeńos y cocinados en calderas para obtener el aceite. Las verdaderas fábricas flotantes, con una rampa que permitía subir el cetáceo completo, sin necesidad de procesamiento previo, aparecieron a partir de 1925 (Basberg, 1998, pp. 31-32).

El sistema moderno de caza de ballenas se introduce en Japón a fines del siglo XIX, pero la caza japonesa tiene un rasgo distintivo pues su objetivo no es el aceite sino la carne de ballena para consumo humano, por lo que el procesamiento de los cetáceos "requiere de procedimientos diferentes a los de la caza noruega de ballenas" (Kalland y Moeran, 1992, p. 79). La caza japonesa se desarrolla sobre la base de tres modelos que surgen un poco antes de la Segunda Guerra Mundial: caza costera en pequeña escala, caza costera en gran escala y caza pelágica. La caza pelágica estaba en manos de tres grandes compañías que procesaban los cetáceos en buques factoría de gran tamaño. Había "compañías más pequeñas, algunas subsidiarias de las 'Tres Grandes', que participaban en la caza costera en gran escala”, caracterizada por el uso de buques cazadores similares a los de la caza pelágica (de 100 a 600 toneladas y tripulados por 12 a 20 hombres) para perseguir los cetáceos y procesar sus carcasas en plantas terrestres. Por el contrario, la caza costera en pequeña escala usaba buques de 50 toneladas equipados con cańones arponeros, siendo las ballenas más pequeñas (minke, piloto y picuda) sus presas más importantes (Takahashi, Kalland, Moeran y Bestor, 1989, pp. 110-119; Kalland y Moeran, 1992, p. 104). Las actividades balleneras japonesas se extienden desde 1957 hacia territorios extranjeros (Tato, 1985), en busca de "nuevos stocks de ballenas", para una "distribución más eficiente de los barcos" o simplemente por "nuevas oportunidades de negocios" (Kasuya, 2009, p. 647).

La observación de las características de las distintas operaciones balleneras comerciales en el mundo permite postular, hipotéticamente (sin desconocer las dificultades inherentes a todo proceso de clasificación), la existencia de cuatro grandes tradiciones balleneras expansivas, que denominamos "vasca", "yanqui", "noruega" y "japonesa”. Estas tradiciones llegan a las costas sudamericanas en diferentes épocas: los vascos a Brasil en 1602; los yanquis a Brasil, Chile y Perú a fines del siglo XVIII; los noruegos a comienzos del siglo XX (a Chile en 1905, a Brasil en 1911 y a Perú en 1924) y los japoneses en la segunda mitad del mismo siglo (a Brasil en 1958, a Chile en 1964 y a Perú en 1968).

La presencia de balleneros foráneos resulta fundamental para explicar el surgimiento de los diversos emprendimientos locales en los países sudamericanos, que integran exitosamente elementos tecnológicos, sociales y productivos propios de los grupos visitantes con conocimientos y prácticas preexistentes en las comunidades costeras tradicionales, sea el procesamiento de ballenas varadas y/o la caza propiamente tal (Quiroz, 2016), configurando, en un complejo juego de transformaciones y continuidades, lo que podemos denominar "tradiciones balleneras locales". ¿Las experiencias sudamericanas son "distintas", a pesar de haber sido expuestas a las "mismas" influencias foráneas, o son similares?

En este trabajo discutimos estas cuestiones solo respecto de la caza tradicional, dejando el problema de la caza moderna para otro momento. 


\section{Marco conceptual}

En la segunda mitad del siglo XVIII las ballenas se transforman en un recurso natural de relevancia, aunque los humanos ya las estaban explotando desde hacía varios siglos. Se las busca especialmente por su aceite, que era usado como combustible para lámparas, en la calefacción y la lubricación de máquinas y como materia prima para la fabricación de jabones, detergentes, pinturas y barnices (Robbins, 1996, p. 75). La naturaleza paradójica de la lógica del capitalismo extractivo se sostiene en una potente contradicción entre la tendencia a crecer y expandirse exponencialmente y la destrucción de los recursos que los modos de producción capitalista extraen y transforman (Harvey, 2014). La persecución de los cetáceos por todos los océanos del mundo provoca que varias especies vean reducido su número, especialmente las ballenas francas, boreales y grises, aunque también los cachalotes sufrieron mermas importantes en sus poblaciones (Smith, Reeves, Josephson y Lund, 2012). La búsqueda incesante del aceite extraído de ballenas y cachalotes da forma a lo que se conoce como la primera "fiebre del aceite" en la historia de la humanidad (Highan y Neves, 2015, p. 115).

La caza de ballenas involucra no solamente las distintas maneras de perseguir y matar a los cetáceos, sino también formas diversas de procesar sus carcasas para obtener los productos que luego serán consumidos y/o comercializados.

Reeves y Smith, con el fin de estudiar el desarrollo de la caza de ballenas en el mundo realizan una revisión sistemática de las formas de caza y proponen usar el término "operación ballenera" como un concepto que permite agrupar las diversas actividades balleneras en 'tipos' y así establecer una verdadera "taxonomía universal" de la caza de ballenas. Este sistema clasificatorio permite "ordenar y manejar las investigaciones sobre la historia de la caza de ballenas [...] en diferentes regiones geográficas y períodos de tiempo" (Reeves y Smith, 2006, p. 83). Una "operación ballenera" habla no solo de las formas de matar los cetáceos, sino también de las maneras de procesar sus carcasas y de consumir y/o comercializar sus productos. Es importante subrayar que cada operación ballenera ocurre en un espacio/tiempo determinado, por lo que la misma tipología permite ordenar las operaciones en una secuencia de "eras balleneras", es decir, "porciones de espacio/tiempo" con continuidades tecnológicas, sociales y culturales específicas, diferentes a las que las preceden (Reeves y Smith, 2006, p. 85).

La "caza aborigen de subsistencia" fue definida por la Comisión Ballenera Internacional (CBI) como aquella cuyo propósito es el consumo local y la desarrollan pueblos aborígenes que comparten fuertes vínculos comunitarios, familiares, sociales y culturales, con una dependencia tradicional de la caza y el uso de las ballenas (Donovan, 1982). Todas las operaciones de caza que no se ajustan a la definición de caza aborigen de subsistencia son consideradas comerciales (Las distinciones entre operaciones de subsistencia y comerciales son problemáticas y han sido discutidas profusamente; ver Moeran, 1992; Freemann, 1993; Takahashi, 1998; Reeves, 2002; Heazle, 2006).

Una operación ballenera puede ser caracterizada por las respuestas a un conjunto finito de preguntas: ¿quién la desarrolla?, ¿qué especies se capturan?, ¿dónde se realiza?, ¿por qué se las caza?, ¿cuándo ocurre?, ¿cómo se hace la captura y el procesamiento de las ballenas? (Reeves y Smith, 2006). El "quién" se refiere a los grupos humanos involucrados en la actividad ballenera. De esta manera, una operación puede definirse por la nacionalidad de las personas que capturan las ballenas, por la nación en cuya tierra se ubica la estación costera o bajo qué bandera operan los buques. También por quienes proporcionan el capital, por el que gobierna las aguas donde ocurre la cacería, o por quienes se benefician del uso o venta de los productos. El "qué" apunta a las especies de cetáceos capturadas. Las operaciones que involucran la caza de diversas especies son muy complejas de definir, pues intervienen distintos factores en la toma de decisiones. No podemos olvidar que, a veces, se persiguen ciertas especies, pero se cazan, en forma oportunista, otras. El "dónde" indica tanto el lugar de captura de las ballenas como también el de residencia de los balleneros. El "por qué" se refiere a los productos buscados, tales como aceite, barbas, carne y huesos, y su posterior destino, sea el autoconsumo o el comercio. El "cuándo" 
corresponde a la época en que la cacería tiene lugar y a su estacionalidad. Finalmente, el "cómo" implica considerar el equipamiento, los métodos y las técnicas usados tanto para capturar como para procesar las ballenas y comercializar sus productos (Reeves y Smith, 2006, pp. 83-84). Estas operaciones experimentan cambios o variaciones en el tiempo, los que debemos relevar sin descuidar, por cierto, las necesarias continuidades que las caracterizan.

Reeves y Smith (2006) agrupan las operaciones balleneras comerciales en seis "eras", que llaman "estilo vasco", "estilo yanqui costero", "estilo yanqui pelágico", "estilo noruego costero", "buque factoría" y "pequeńa escala". Los estilos balleneros vasco, yanqui costero y yanqui pelágico forman parte de la denominada caza tradicional de ballenas; los estilos noruego costero, buque factoría y pequeña escala, de la caza moderna. El "estilo vasco" se caracterizaba por el uso de botes abiertos, propulsados a remo y/o vela, desplegados desde la playa o desde buques anclados cerca de la costa, y la utilización de arpones y lanzas manuales. El "estilo yanqui costero" era muy similar al estilo vasco, pero usaban además botes a motor para el remolque de las ballenas a la costa, y armas de fuego experimentales y explosivos como un complemento a los arpones y lanzas manuales. El "estilo yanqui pelágico" usaba los mismos implementos que el yanqui costero, pero la ballena era procesada al costado de un buque-nodriza y el tocino transformado en aceite en hornos instalados a bordo. Los "estilos" de la caza moderna no los abordaremos aquí.

En este trabajo, que busca mejorar el conocimiento que tenemos de la historia y antropología de la caza de ballenas en las costas sudamericanas, conservamos el concepto "operación ballenera" pero reemplazamos el de "era ballenera", en nuestra opinión más asociado a la geología y/o la historia natural, por el de "tradición ballenera", más propia de la disciplina antropológica. Entendemos la tradición ballenera como "una forma particular de organización social, que integra habilidades y conocimientos individuales y colectivos, reglas de captura de una o varias especies de cetáceos, su procesamiento y la distribución y uso de los productos, trasmitidos a través de generaciones" (Lindquist, 1994, p. 16). Debemos tener en cuenta que la tradición no es solo un patrón heredado de pensamiento y/o acción, o una práctica específica de largo plazo transmitida generacionalmente, sino también una interpretación del pasado mediatizada simbólicamente en el presente, en una transformación permanente, con continuidades y discontinuidades (Van Ginkel, 2007, p. 9). No usamos el concepto de cultura ballenera pues este considera "una adaptación marítima, tecnológica y económicamente especializada en la explotación de cetáceos, y donde las ballenas son particularmente importantes en otras esferas de la vida cotidiana" (Lindquist, 1994, p. 15), aspectos no siempre presentes en el marco de la caza comercial.

\section{Metodología}

El estudio de las operaciones balleneras sudamericanas se realiza mediante lo que hemos denominado etnografía retrospectiva. El término "etnografía retrospectiva" nos ha servido para nombrar un enfoque que involucra el uso integrado de diversos tipos de fuentes: "recortes" de documentos administrativos, científicos y literarios, de noticias y entrevistas de prensa, depositados en archivos; "recuerdos" de personas que pudieron observar directamente la experiencia ballenera o les hablaron de ella; "ruinas", testimonios y huellas materiales relevadas en visitas a los lugares donde la caza de ballenas se produjo (Quiroz, 2015, 2016). La etnografía retrospectiva es una herramienta que permite estudiar "el pasado de la misma manera como un antropólogo aborda una sociedad exótica” (Thomas, 2009, p. 2) y analizar un modo de vida del ayer como si fuera contemporáneo, usando "los mejores equivalentes históricos de las observaciones de los etnógrafos" (Tilly, 1978, p. 210). El concepto ha sido usado de diversas maneras por antropólogos e historiadores, reflejando su naturaleza algo ambigua o, al menos, polisémica (Gonçalvez, 2009; Lennartsson, 2011; Driessen, 2013; Bezerra, 2015). Estas etnografías retrospectivas, dado el carácter globalizado de las operaciones balleneras, son siempre comparativas y multisituadas (Marcus, 2001).

El objeto de preocupación de la etnografía retrospectiva es un conjunto de eventos del pasado, es decir, sucesos o problemas que no pueden ser observados 
directamente, por lo que su realización "coloca al investigador frente al dilema de apelar a técnicas de recolección de datos más ligadas a otras disciplinas, como la historia" (Gil, 2010, p. 250). Las operaciones balleneras sudamericanas son "eventos del pasado", ninguna de ellas se realiza en la actualidad. La información sobre ellas debería estar almacenada en "archivos", espacios donde habitualmente es el historiador y no el antropólogo quien desarrolla su "trabajo de campo" y elabora sus principales herramientas analíticas. Pero estos archivos están "disponibles" para cualquiera que desee usarlos, entre ellos, por supuesto, los antropólogos. El problema surge cuando estos "archivos" no son lo suficientemente variados y densos como para permitirle al etnógrafo obtener respuestas a sus preguntas.

Este trabajo se basa principalmente en una revisión exhaustiva de la información que se ha publicado en libros y revistas sobre la caza tradicional de ballenas en las costas sudamericanas. Se ha realizado un trabajo intensivo de investigación bibliográfica y documental que nos permitió reunir una serie de "recortes", un conjunto de textos que dan cuenta de la práctica ballenera en las costas sudamericanas. No hemos incluido en esta oportunidad los "recuerdos" y las "ruinas", que constituyen etapas posteriores en el desarrollo de este estudio.

Para el estudio de la documentación se consideró en primera instancia un análisis formal de cada documento, orientado a describir y contextualizar la información contenida, de modo de generar una valoración estricta de los antecedentes. La información fue registrada en una ficha tipo y administrada como una base de datos. Cada documento fue sometido a un análisis de contenido simple a partir de una prospección proyectiva que permita fijar los principales ejes temáticos y núcleos de información. Los ejes podrán ser aislados para ser comparados y relacionados entre los diversos documentos relevados, que permita generar las interpretaciones. Finalmente, se procedió a comparar la información obtenida sobre las tradiciones balleneras en los distintos países sudamericanos, con el fin de conseguir patrones comunes, pero también indicar sus diferencias y dar cuenta de las transformaciones ocurridas a través del tiempo.
El conocimiento que tenemos de estas operaciones balleneras es bastante desigual pues algunas, como las chilenas, las conocemos de cerca y bastante bien, mientras las otras, brasileñas, argentinas, uruguayas y peruanas, únicamente de manera indirecta y en forma muy fragmentaria. Nuestras reconstrucciones son solo parciales y, sin duda, una investigación más profunda de las operaciones menos conocidas puede ayudar a comprender de mejor manera su situación tanto en el espacio como en el tiempo.

\section{Resultados}

Reeves y Smith elaboran una lista, no exhaustiva, de 113 operaciones balleneras por todo el mundo, de las que solo siete son ubicadas en las costas sudamericanas: dos en Brasil, una en Argentina, tres en Chile y una en Perú (2006, pp. 99-101). De las siete operaciones balleneras sudamericanas reconocidas solamente dos corresponden a operaciones balleneras tradicionales: una del estilo vasco en Brasil y otra del estilo yanqui costero en Chile. Sin embargo, una simple revisión de la literatura revela la existencia de otras operaciones, no consideradas en dicha lista, cuestión que los autores preveían pues esperaban que "otras investigaciones fueran capaces de expandir considerablemente el número de operaciones reconocidas, incluyendo tanto algunas recientes como otras antiguas" (Reeves y Smith, 2006, p. 92).

En este trabajo hemos logrado determinar la presencia de tres núcleos con caza tradicional de ballenas, sin mayor contacto entre ellos: (a) Brasil, (b) Uruguay-Argentina, (c) Chile-Perú.

Las primeras operaciones balleneras sudamericanas comienzan en 1602 en las costas de Bahía, Brasil. En la categoría de "caza tradicional" podemos agrupar estas operaciones costeras brasileñas con las breves operaciones costeras realizadas por la Real Compañía Marítima en Argentina (Puerto Deseado) y Uruguay (Maldonado) y todas aquellas operaciones balleneras, tanto pelágicas como costeras, desarrolladas en las costas del Pacífico producto de la influencia de balleneros extranjeros, principalmente angloestadounidenses y franceses, que involucraron capitales y personas, nacidas o residentes en países como Chile y Perú. No hemos detectado en los 
países del Atlántico (Brasil, Uruguay o Argentina) una respuesta semejante de sus empresarios ante las incursiones de los balleneros angloestadounidenses en sus costas. Estas operaciones perduran hasta bien entrado el siglo XX en Brasil, Chile y Perú. No queremos cerrar la posibilidad de agregar, en un futuro cercano, otras operaciones balleneras en las costas sudamericanas, de las que, hasta el momento, no tenemos mayores indicios. Probablemente un estudio más detallado de las operaciones balleneras peruanas permitirá distinguir un núcleo chileno y otro peruano, pero, por el momento, eso no es posible.

Pasaremos ahora a describir cada una de estas operaciones balleneras considerando, en la medida que sea posible, responder a las preguntas ¿quién la desarrolla?, ¿qué especies se capturan?, ¿dónde se realiza?, ¿por qué se las caza?, ¿cuándo ocurre?, ¿cómo se hace la captura y el procesamiento de las ballenas?

\section{Brasil}

Los balleneros vascos se instalan en las costas atlánticas sudamericanas a comienzos del siglo XVII. Felipe III, rey de Espańa y Portugal, otorga el 9 de agosto de 1602 "al Capitán Pedro de Urecha y a su socio Julián Miguel, vecinos de Bilbao [...] el privilegio de pescar ballenas en las costas de Brasil, por un plazo de diez ańos" (Ellis, 1969, p. 31). La Corona ibérica buscaba "aprovechar la larga tradición y experiencia de dichos pescadores para implementar una antigua y lucrativa actividad económica occidental en la colonia" (Castellucci, 2009, pp. 3334; Ellis 1969, pp. 31-33). La isla de Itaparica, en Bahía, fue la localidad escogida. Los comerciantes vascos venían cada año de Bilbao, con dos o tres veleros pequeños y una tripulación principalmente constituida por vascos franceses, quienes cazaban las ballenas en chalupas con arpones manuales, de las que obtenían el aceite y las barbas. Estos procesos fueron observados por los colonos portugueses en Brasil, quienes terminaron aprendiendo el oficio, de modo que cuando la licencia caducó y los vascos no continuaron, los colonos se pudieron hacer cargo de la industria.

La primera armazón propiamente brasileña fue establecida en la isla de Itaparica en 1613 (Edmunson y Hart, 2014, pp. 34-38). En 1614 se establece un monopolio real para la pesca de la ballena, "pues siendo pez real, el cetáceo era propiedad de la Corona", y se reglamentan contratos con los particulares interesados en cazarlas (Ellis, 1969, p. 35). El núcleo de la actividad ballenera eran las "armazones", es decir, las estaciones costeras construidas para el procesamiento de las ballenas, pero que en realidad eran emprendimientos dedicados a la captura de estos cetáceos y al aprovechamiento de sus partes, constituidos por un conjunto que comprendía edificaciones, equipamientos y mano de obra que dependía mucho de la estacionalidad en las migraciones de los cetáceos a lo largo de la costa. Una de las características que se ha resaltado en estas operaciones es la participación de mano de obra esclava, principalmente en las instalaciones procesadoras, pero también en las chalupas cazadoras (Castellucci, 2009).

La especie de cetáceo capturada en las armazones brasileñas durante la época colonial fue la ballena franca austral. La caza de ballenas se extiende desde Bahía hacia el sur por todo el litoral brasileño, Río de Janeiro, São Paulo, llegando, "después de casi ciento cincuenta años" (a mediados del siglo XVIII) hasta la región sureña de Santa Catarina con "las técnicas de arponeo, captura de los cetáceos, manipulación de la gordura y manufactura de aceite", traída por los vascos y adaptada por los brasileńos a su propia estructura económica y social (Ellis, 1969, p. 41).

En 1801 se acaba este sistema de contratos para las pesquerías de ballena, pero la actividad se mantiene, con vaivenes, hasta muy avanzado el siglo XX, en las armazones de Porto dos Santos y São Joao de Manguinhos, en Itaparica, Bahía, de Caravelas, al sur de Bahía y de Lagoinha, Garopaba e Imbituba, en Santa Catarina. En Imbituba se cazó ballenas con el modelo tradicional hasta 1973.

\section{Argentina/Uruguay}

Las operaciones balleneras costeras brasileñas no fueron las únicas en el Atlántico, pues a fines del siglo XVIII comenzó la experiencia de la Real Compañía Marítima, que podríamos incluir en la tradición vasca, pero con algunos matices.

Los espańoles, en sus colonias sudamericanas, no solo estaban inquietos por las incursiones de los 
balleneros ingleses y estadounidenses, sino también muy interesados en los beneficios que ofrecía la caza de ballenas. Rondaba la idea de formar una empresa que pudiera desarrollar la pesca de la ballena y al mismo tiempo defender los intereses económicos y políticos de la Corona española en suelo americano. Finalmente, ante la gran cantidad de buques norteamericanos, ingleses y franceses que en los últimos años cruzan los mares considerados hispanos con la finalidad de "pescar la ballena" son una real amenaza política y económica, se funda la Real Companía Marítima por Cédula de Su Majestad del 19 de septiembre de 1789, promovida por Antonio Sáñez Reguart (Martínez Shaw, 2008, p. 599). El objetivo de la compañía era "hacer la pesca en los mares de mis dominios en Europa, África y América, de todas las clases de peces propios para salar y curar, y beneficiarlos de esta o cualquiera otras maneras, como también la pesca de ballena y de otros peces de grasa para reducirlos a ella" (Cédula de Su Majestad para el establecimiento de la Real Compañia Maritima, 1789), pero también pretendía poblar la región patagónica austral y controlar la presencia permanente de naves inglesas, norteamericanas y francesas, que ponían en peligro el control hispano sobre estas regiones.

El interés español era levantar "un armazón de pesca de ballenas como los que tienen los portugueses en Santa Catalina, procurando a este intento adquirir sujetos prácticos a toda costa", como se indica en la Real Orden del 24 de febrero de 1778 al virrey de Buenos Aires (Montalbán y Capdevila, 2013, p. 101). La primera expedición, compuesta por dos fragatas y dos goletas, sale del puerto de Santander el 26 de noviembre de 1789, al mando de Juan $\mathrm{Mu}$ ñoz con cerca de 250 hombres, y arriban a Puerto Deseado, Argentina, en los primeros meses de 1790. Las ballenas se capturaban con chalupas y arpones manuales, de la misma manera como los vascos lo hacían desde el siglo XI de nuestra era. La ballena franca era el blanco de estas operaciones balleneras. La compañía construye instalaciones balleneras en Puerto Deseado, Argentina, y luego en 1791 en Maldonado, Uruguay, pero sus operaciones no tuvieron mucho éxito y fue suprimida, por decisión real, el 10 de julio de 1803 (Silva, 1978). La totalidad de ballenas capturadas no habría excedido, según los especialistas, la treintena (Aguilar, 2013, p. 26). Las razones de su fracaso tienen que ver con "sus insuficientes recursos materiales y financieros", su nunca resuelta dualidad estructural (empresa pesquera/empresa colonizadora) y "una negativa coyuntura bélica desencadenada a partir de 1796" (Martínez Shaw, 2008, p. 594).

\section{Chile/Perú}

La influencia de los balleneros extranjeros en las costas sudamericanas occidentales genera el surgimiento de operaciones balleneras pelágicas muy similares, pero también otras, de naturaleza costera, con diferencias importantes. Las describiremos de manera separada aunque están interrelacionadas.

\section{Operaciones pelágicas}

Los balleneros europeos ingresan al Pacífico en 1789 y su influencia genera, entre 1820 y 1854 , una serie de proyectos que involucran capitales y tripulaciones chilenas y peruanas para perseguir ballenas con el modelo de la caza pelágica, siendo el más notable el emprendido por la Casa López y Sartori, comerciantes y armadores de Valparaíso, que envían dos expediciones balleneras al mar de Okhotsk, una región situada en el extremo nororiental de la Rusia asiática. Entre 1860 y 1870 la participación chilena aumenta en forma significativa, llegando a conformar una flota de diecinueve buques involucrados en la caza de la ballena desde Talcahuano, Valparaíso y Caldera. Recorrían las costas de Chile, Perú, Ecuador (islas Galápagos incluidas) y Panamá en busca de cachalotes y ballenas jorobadas en viajes que duraban cerca de nueve meses. Desde Talcahuano salieron también algunas expediciones al sur para cazar ballenas en los mares antárticos. El modelo de caza pelágica se mantiene, disminuido pero vigente hasta 1922, cuando el barco James Arnold realiza su último viaje, por encargo de José Maritano, comerciante de Talcahuano que había adquirido los bienes de la sociedad Toro \& Martínez, sucesora de Mathieu \& Brańas.

La principal compañía ballenera chilena que operó en forma pelágica fue la Compañía Chilena de Balleneros de Valparaíso, puerto que a mediados del siglo XIX se había insertado de una manera ejemplar "en el 
proceso capitalista global", consolidándose como un "gran centro mercantil y financiero del país" y concentrando "un importante número de las emergentes sociedades anónimas destinadas a la formación de nuevos capitales y a su inversión en diferentes actividades de la economía nacional" (Cavieres, 1999, p. 139). Los recursos materiales de la compañía están representados fundamentalmente por los buques, con sus aparejos, equipos y herramientas, y también por las oficinas administrativas, refinerías y bodegas. La Compañía Chilena de Balleneros comenzó a operar en 1871 con siete buques. La empresa tenía su refinería y bodegas en caleta Las Habas, en el puerto de Valparaíso (El Mercurio de Valparaíso, 6 de julio, 1872). La mayoría de los capitanes y oficiales de los buques eran extranjeros, principalmente estadounidenses e ingleses. La tripulación de cada buque era mixta, formada en porcentajes variables por chilenos y extranjeros. No tenemos mayores antecedentes de las personas que trabajaban en la refinería, oficinas y bodegas. Los productos que la empresa ofrece son, en un principio, aceite de ballena y aceite de cachalote. La compañía publica un aviso en la prensa a fines de 1871 donde asegura que "está ya en aptitud para entregar aceite clarificado, acondicionado en tarros, cajones o barriles, según la voluntad de los compradores" (El Mercurio de Valparaiso, 14 de diciembre, 1871). Se distinguen tres etapas en el desarrollo de la Compañía Chilena de Balleneros. Primero, un momento exploratorio, entre 1871 y 1880 , luego una etapa de estabilización, con un desarrollo sostenido de la compañía, entre 1880 y 1914, y finalmente, el ocaso, que termina con el último viaje del Josephine en 1917.

En Talcahuano la situación fue algo diferente. Los comerciantes de Talcahuano y Concepción G. Crosby, Burton \& Trumbull, Mathieu \& Brańas, P. del Río, R. Fuentes y S. F. Lindsay se asocian y sus nuevos buques pasan a denominarse, usando topónimos regionales, Concepción, Bio Bio, Tumbes, Hualpén y Talcahuano. En 1870 la flota ballenera de Talcahuano alcanzaba los quince buques, más del doble que los de Valparaíso. Esta sociedad, denominada Asociación Penquista de Balleneros, estaba formada por "empresarios regionales [que] tentaron suerte en la caza de ballenas en las bahías de Concepción y Arauco y aún más allá, en toda la costa del Pacífico Sur", entre los que se encontraba Pedro del Río, "agricultor y destacado filántropo penquista”, que participó en una sociedad en Talcahuano, "la que fue dotada de nueve excelentes barcos [...], además trajeron de Estados Unidos materiales y trabajadores expertos para la construcción de embarcaciones menores". El negocio no resultó lo esperado y se liquidó "la sociedad por la ninguna protección del gobierno, costándome a mí, uno de los socios (Pedro del Río), 30 mil pesos oro de 548 peniques" y "grandes sumas de dinero a mis ya fenecidos amigos Burton, Trumbull, Fuentes, García, Mathieu y Brañas" (Cartes, 2009, p. 42). Entre 1871 y 1872 se vende la mayoría de los buques que estaban cazando ballenas desde Talcahuano, quedando solamente tres barcas, que operaban con viajes anuales a la zona del golfo de Panamá (Star \& Herald, Panamá, 4 de junio de 1872, 6 de junio de 1872, 29 de junio de 1872). El "boom" de la pesca de ballenas desde Talcahuano no duró más de tres años (1868-1871). La caza de ballenas continuó en forma esporádica y de manera reducida hasta el último viaje del James Arnold en 1922, "con un capitán náutico, otro de pesca, dos o tres pilotos, y veinte a veinticinco hombres" (Sandoval, 1978, p. 235). La revisión documental ha permitido identificar un total de 38 buques que bajo bandera chilena realizaron entre 1856 y 1922 alrededor de 370 expediciones balleneras desde sus puertos, Valparaíso, Talcahuano y Caldera, a los caladeros de ballenas del Pacífico.

Con respecto a operaciones pelágicas balleneras peruanas, tenemos indicios de que también existieron, aunque la información no es muy abundante. La presencia ballenera estadounidense en las costas peruanas fue importante y es bastante conocida (Lofstrom, 1996; Flores, 2010, 2011). Sin embargo, los historiadores resaltan el poco interés que despertó la pesca de ballenas entre los comerciantes peruanos en los primeros ańos republicanos, aunque Paita fuera considerado "el puerto ballenero de la costa occidental de América del Sur" (Denegri, 1977, p. 394). Se pueden encontrar en las fuentes, sin embargo, algunas excepciones. En 1847 aparece dedicado a la pesca de ballenas el bergantín Callao, de 147 toneladas, de propiedad de Thomas Jump y capitaneado por John Brown (Denegri, 1977, pp. 400-401). En la nómina de la Marina Mercante del Perú de 1853 aparecen cuatro veleros ocupados en la pesca de ballenas: la fragata Sofía Somonte, 349 toneladas, 
de Manuel Somontes, que también es su capitán; la barca Vencer, 203 toneladas, de Thomas Jump y capitaneada por John Best; la barca Joven Adonis, 147 toneladas, de Antonio Eugenio y capitaneada por William Mitchell, y el bergantín goleta Marion, 62 toneladas, de W. Johnston, cuyo capitán se desconoce "pues el buque estaba carenándose" (Denegri, 1977, p. 401). Estas excepciones marcan, sin duda, el hecho de que la caza pelágica peruana, aunque presente, no tuvo la magnitud ni la importancia de las operaciones chilenas, reconocido por los propios estudiosos de la historia ballenera de ese país (Coker, 1908).

\section{Operaciones costeras}

La influencia estadounidense se sentirá también en el desarrollo de operaciones balleneras costeras en pequeña escala, que hemos denominado "caza tradicional de ballenas", que utilizaban botes abiertos y arpones de mano y procesaban sus carcasas en instalaciones costeras bastante precarias, como las de José Olivares, en caleta Tumbes, Talcahuano, y Juan Macaya en Puerto Norte, isla Santa María. La caza costera de ballenas se inicia en la bahía de Concepción en la década de 1830. Sin embargo, las primeras referencias oficiales sobre la existencia de pescadores costeros de ballenas las encontramos en un informe escrito en 1854 por el intendente de Concepción, basado en los datos que le entregara Juan Williams, en esa fecha gobernador marítimo de Talcahuano. Manifiesta que en 1853 "once chalupas hacen la pesca de la ballena, cruzando a las inmediaciones de las costas", agregando que son 66 los hombres "ocupados en la pesca de la ballena” (Sotomayor, 1854, pp. 51, 54). En el Censo General de Población de la República de Chile de 1854 aparecen registrados en Tumbes, San Vicente y Talcahuano 33 balleneros, 30 chilenos y 3 extranjeros (1854, ANH-IC, vol. 421 , s.f.). Otros textos indican que habría sido José Olivares el "fundador de esta industria" en Tumbes, Talcahuano, donde habría estado cazando ballenas desde 1840 y su nombre "se conserva rodeado de una cierta legendaria aureola, que el tiempo agranda y ennoblece" (Dublé Urrutia, 1905, p. 4). El gobernador marítimo de Talcahuano Carlos Pozzi señala en 1875 "que la pesca de ballenas en esta costa generalmente tiene lugar desde abril hasta noviembre" y resalta que "esta clase de industria es mui benéfica para formar hombres arrojados i acostumbrados a los peligros del mar" (Pozzi, 1875, pp. 269-270).

Los pescadores de ballenas comenzarán a ocupar paulatinamente todo el litoral del centrosur de Chile en la segunda mitad del siglo XIX. En marzo de 1862 los balleneros de Talcahuano instalan una faena en la desembocadura del río Lebu, a cargo de José Morán. Lebu será el extremo meridional de una extensa zona de captura para los pescadores de Talcahuano. La autorización otorgada en 1869 a José Olivares, de Tumbes, para "salir a la pesca de ballenas en embarcaciones menores", delimitaba claramente un territorio de pesca en la segunda mitad del siglo XIX, que estaba comprendido por "la isla Santa María, costa de Arauco i Lebu" (La Tarántula, Concepción, 1 de marzo, 1869).

En las postrimerías del siglo XIX, llegan hasta el río Maullín y la Isla Grande de Chiloé. José Gómez, de Chonchi, Chiloé, recordaba que su abuelo,

Carmelo Gómez Vera, su hermano Delfín Gómez Vera y gente de afuera se dedicaban a cazar ballenas, la cazaban con arpones. Primero se acercaban con botes y arponeaban las ballenas y tenían como 200 metros de lazo para que se vaya al fondo y después flotaba. En ese momento decían que le tiraban como unas lanzas para que se desangre y los botes, que eran 3 o 4, la tiraban hacia fuera en la reventazón de la ola, entonces la misma ola la tiraba a tierra. Cuando la ballena varaba en la playa le sacaban la barba, eso lo aprovechaban [...]. Yo no vi cazar ballenas, sólo le digo lo que me contaron porque era muy chico en esa época. De las ballenas los viejos de antes aprovechaban muy poco porque no le sacaban la grasa ni la carne, eso lo dejaban para que lo coman los pájaros" (Entrevista a José del Carmen Gómez Álvarez, Chonchi, 2008, en Montiel, 2010, pp. 289-290). 
Probablemente la primera década del siglo XX sea el momento de mayor desarrollo de la caza costera en el litoral chileno. Desde 1920 la caza tradicional de ballenas comienza a declinar, hasta desaparecer por completo hacia 1950. Su decaimiento se debe, al menos parcialmente, a la formación de empresas balleneras modernas en la primera década del siglo XX, tanto en Punta Arenas como en Valdivia.

Existe algo de información sobre las experiencias de caza de ballenas en pequeña escala en el norte de Perú (Coker, 1908). En 1890 Mateo Zaput, de Dubrovnik, habría iniciado la caza costera de ballenas en Tumbes (Perú), procesándolas para obtener aceite que exportaba como lubricante para maquinarias (Meseldzic, 1985, p. 116). En 1907 los habitantes de la boca del río Tumbes explotaban "una flota de veintiuna embarcaciones menores", con 97 toneladas en total, con las que "se dedican también a la pesca de ballenas, especialmente de agosto a noviembre" (Melo, 1915, p. 56). En Tumbes había "dos compañías para la pesca de ballenas", una dirigida por Nicanor Delgado y la otra "por el señor Maceda". Ambas empresas "usaban el mismo tipo de botes y aparatos, y se ocupaban de esta actividad según las circunstancias y conveniencias de las respectivas compañías". Cada una tenía "cuatro botes equipados y una o dos lanchas" y usaban "exclusivamente el arpón a mano” (Palacio Rodríguez, 1991, p. 345).

La única ballena que se caza en la zona es la jorobada, y "el aceite [es] el único producto comercial que se aprovecha, pues la barba es completamente desatendida". La temporada de caza se extiende "de junio a octubre" (Coker, 1908).

\section{Discusión: un ejercicio comparativo}

Podemos realizar una serie de distinciones en las diversas operaciones balleneras estudiadas. La primera distinción se relaciona con la oposición Atlántico (Brasil, Uruguay y Argentina) vs. Pacífico (Chile y Perú), sus similitudes y diferencias. La segunda tiene que ver con la oposición caza pelágica vs. costera y sus vinculaciones, no solamente teóricas sino también prácticas. La tercera tiene que ver con la continuidad de los modelos y las transformaciones experimentadas por ellos en el tiempo (Tabla 1).

Tabla 1. Cuadro comparativo de operaciones balleneras tradicionales sudamericanas (siglos XVII-XX).

\begin{tabular}{|c|c|c|c|c|c|c|}
\hline & $\begin{array}{c}\text { Quiénes } \\
\text { (balleneros) }\end{array}$ & $\begin{array}{c}\text { Qué } \\
\text { (especies) }\end{array}$ & $\begin{array}{l}\text { Dónde } \\
\text { (lugares) }\end{array}$ & $\begin{array}{l}\text { Cuándo } \\
\text { (siglos) }\end{array}$ & $\begin{array}{c}\text { Por qué } \\
\text { (productos) }\end{array}$ & $\begin{array}{l}\text { Cómo } \\
\text { (técnica) }\end{array}$ \\
\hline Brasil & $\begin{array}{l}\text { Concesionarios } \\
\text { y pescadores }\end{array}$ & $\begin{array}{l}\text { Ballena franca y } \\
\text { jorobada }\end{array}$ & $\begin{array}{l}\text { Costa de Brasil } \\
\text { entre Bahía y } \\
\text { Santa Catarina }\end{array}$ & XVII-XX & Aceite y barbas & $\begin{array}{l}\text { Chalupa, arpón } \\
\text { de mano y lanza }\end{array}$ \\
\hline $\begin{array}{l}\text { Argentina y } \\
\text { Uruguay }\end{array}$ & $\begin{array}{l}\text { Estado y } \\
\text { pescadores }\end{array}$ & Ballena franca & $\begin{array}{l}\text { Maldonado y } \\
\text { Puerto Deseado }\end{array}$ & XVIII-XIX & Aceite y barbas & $\begin{array}{l}\text { Velero, chalupa, } \\
\text { arpón de mano } \\
\text { y lanza }\end{array}$ \\
\hline $\begin{array}{l}\text { Chile y Perú; } \\
\text { pelágica }\end{array}$ & $\begin{array}{l}\text { Comerciantes } \\
\text { nacionales y } \\
\text { extranjeros; } \\
\text { Pescadores y } \\
\text { marineros }\end{array}$ & $\begin{array}{l}\text { Ballena franca, } \\
\text { jorobada y } \\
\text { cachalote }\end{array}$ & $\begin{array}{l}\text { Entre Panamá e } \\
\text { isla Mocha }\end{array}$ & XIX-XX & $\begin{array}{l}\text { Aceite, barbas y } \\
\text { esperma }\end{array}$ & $\begin{array}{l}\text { Velero, chalupa, } \\
\text { arpón de mano, } \\
\text { lanza y bombo } \\
\text { lanza }\end{array}$ \\
\hline $\begin{array}{l}\text { Chile y Perú; } \\
\text { costera }\end{array}$ & Pescadores & $\begin{array}{l}\text { Ballena franca y } \\
\text { jorobada }\end{array}$ & $\begin{array}{l}\text { Entre } \\
\text { Talcahuano y } \\
\text { Chiloé } \\
\text { Norte de Perú }\end{array}$ & XIX-XX & Aceite y barbas & $\begin{array}{l}\text { Chalupa, arpón } \\
\text { de mano, lanza y } \\
\text { bombo lanza }\end{array}$ \\
\hline
\end{tabular}




\section{Las operaciones balleneras en el Pacífico y el Atlántico}

Las operaciones costeras, chilenas y peruanas, eran muy semejantes, tecnológicamente hablando, a las empleadas por los brasileños en el Atlántico. Normalmente había un vigía ocupado en el avistamiento de los cetáceos. En la isla Santa María, cuando el tiempo lo permite,

siempre hay un hombre apostado en una de las cumbres de la isla, de las más inmediatas a la playa [...] explorando el horizonte con ayuda de un anteojo, i cuando ve aproximarse un ejemplar, anuncia la presencia del monstruo a sus compañeros de embarcación, procurando hacerlo con el mayor sigilo para que su descubrimiento no sea aprovechado por los demás colegas de labores, que como el, están en acecho de su presa (Castillo, 1906, p. 5).

Una vez avistada la presa, se aparejaban y lanzaban al agua las chalupas: "en la proa el trancador, o matador, en la popa, el piloto (generalmente el dueño de la embarcación) y en los bancos cuatro bogadores, dispuestos a remar sin descanso, en silencio y sin miedo, 10, 12 y hasta 24 horas seguidas" (Dublé Urrutia, 1905, p. 4). Se inicia la persecución. Una vez acorralada la ballena, con la chalupa a su lado, el piloto da la orden de 'trancar' y 'el 'trancador' se pone de pie en la proa i cogiendo el arpón [...] lo lanza como una flecha sobre alguno de los puntos orgánicos de la ballena, de modo de traspasarle el corazón o alguna otra parte igualmente delicada" (Dublé Urrutia, 1905, p. 1). Si el arponero tiene éxito, se dice que la ballena ha sido 'fijada' (Castillo, 1906, p. 5). Al 'fijar' la ballena, uno de los bogadores, que ha dejado de remar, para controlar su calentamiento por fricción "moja la línea, variando en alguna cierta cantidad de agua, que luego se filtra por los numerosos agujeros practicados en el fondo" (Castillo 1906, p. 5). Herida, la ballena huye "arrastrando hasta ochenta i cien brazas el cabo de línea que va unido al arpón" (Dublé Urrutia, 1905, p. 1).

En la chalupa los bogadores dejan los remos y todos "se cogen al cabo de línea que jamás se amarra al barco, largando y largando cabo, hasta que se siente que la ballena deja de bajar, comienza a huir en dirección horizontal o bien vuelve a salir sobre las olas" (Dublé Urrutia, 1905, p. 5). En ese momento, los tripulantes "proceden a recoger la línea con prontitud, hasta notar en ella una marca que les revela la proximidad del cetáceo, que busca la superficie para poder respirar i que se encuentra desde este momento a tiro de lanza”. Para maniobrar con la lanza, se requiere que el timonel, ayudado del resto de la tripulación, coloque el bote "de manera que pueda desde ahí lanzar el animal en el mismo costado donde fue fijado por el arpón. Se da uno i hasta tres lanzazos, o más bien dicho, le da los que alcanza, recogiendo el arma con presteza, inmediatamente que se hace uso de ella”. La ballena, entonces, sintiéndose nuevamente herida, ya de muerte, "se sumerge con lentitud, inclinándose comúnmente de un lado a otro, agoniza tiñendo el agua con su sangre, hasta que luego queda completamente inanimada" (Castillo, 1906, p. 5). Finalmente, la ballena "se vuelve de espaldas" y muere (Dublé Urrutia, 1905, p. 1). Luego, "los esforzados bogadores sumergen sus remos y avanzan arrastrando el monstruo lentamente, guiándose a menudo solo por la luz del faro, sin divisar la playa de la isla" (Castillo, 1906, p. 6). Esta operación es muy fatigosa y, en el caso de los pescadores de Tumbes, "suele durar hasta tres i cuatro días, según la distancia de Tumbes a que se verificó la caza. Una legua se anda, a veces, en cuatro o cinco horas" (Dublé Urrutia, 1905, p. 2).

Una vez que la ballena llega a la playa, "entre el general entusiasmo de la gente" se procede a beneficiarla, cortando "el animal en tres partes i haciendo tres trozos de la cabeza, el cuerpo i la cola" (Dublé Urrutia, 1905, p. 2). En la playa se destrozan estas partes con 'espeles', cuchillos triangulares especiales para el tocino. Los trozos o 'tajadas' de tocino son de una vara de largo (Castillo, 1906, p. 6). Este tocino "se hierve en fondos grandes de hierro i así se saca el aceite" (Dublé Urrutia, 1905, p. 2). La utilización de las carcasas no era del todo eficiente: en la isla Santa María "el cadáver queda botado en la playa después de sacarle la grasa, i no toda, aprovechándose de su carne las gaviotas, jotes, tiuques i pájaros carneros; además, en todo tiempo, se deja sentir un mal olor aún a distancias considerables, i principalmente en el verano se respira un ambiente de una fetidez pútrida insoportable" (Castillo, 1906, p. 7). 
¿Cuáles son las diferencias con las operaciones costeras brasileñas? Prácticamente ninguna. Según los testimonios, la caza de ballenas era realizada con cuatro a seis "lanchas de arponeo", propulsadas a remo y vela. El bote tenía unos diez a doce metros de largo y un poco más de dos metros de ancho. La proa y la popa eran "apuntadas", para hacerlas más maniobrables. La tripulación de cada bote constaba de seis remeros, un arponero y el timonel, que muchas veces era el dueño de la embarcación (Edmunson y Hart, 2014, pp. 43-44). Hay algunas diferencias en la organización social de las operaciones, por ejemplo, el uso de mano de obra esclava, el establecimiento de contratos con el gobierno, pero no en sus aspectos tecnológicos.

Tampoco hay diferencias entre las operaciones costeras brasileñas con las breves operaciones balleneras en las costas de Uruguay y Argentina.

La gran distinción que existe entre las operaciones balleneras es la relevancia de la influencia norteamericana, muy importante en las costas pacíficas, prácticamente inexistente en las costas atlánticas, a pesar de que los balleneros de Nueva Inglaterra recorrieron ambos océanos con bastante frecuencia. Esto tiene algunos efectos en la organización de las operaciones balleneras, bastante controladas por los Estados en el caso de las atlánticas y con una injerencia mínima en el caso de las pacíficas.

\section{Operaciones costeras y pelágicas}

La caza pelágica y la caza costera son dos sistemas tecnológicos completamente diferentes pero relacionados entre sí. La finalidad de ambos sistemas es la obtención de aceite y barbas de ballena, pero las formas de producción no son las mismas. En la caza pelágica se utilizan veleros y botes balleneros. Estos botes son los mismos que se usan en la caza costera. Las herramientas utilizadas en la captura y procesamiento de los cetáceos son muy similares en ambas modalidades. La diferencia radica en que en la caza pelágica el procesamiento se realiza al costado del buque y a bordo, en cambio en la caza costera los animales se benefician en precarias instalaciones situadas en la orilla o bien directamente en la playa. La comercialización de los productos obtenidos por la caza costera es realizada directamente por los balleneros o bien vendida a las empresas dedicadas a la caza pelágica, que se transforman en intermediarios para sus productos.

En un trabajo escrito por Julio Puga, premiado por la Comisión de la Exposición Nacional de 1884, se indica que en Chile

se dedica a la explotación de la pesca de altura la 'Compañía Chilena de Balleneros' que fue legalmente establecida en Valparaíso en 1871, por varios comerciantes de esa plaza, y como su nombre lo indica, la explotación recae exclusivamente en la pesca de ballenas, operación que ejecutan en alta mar. Cuenta esta compañía, hoy día (setiembre de 1884) para hacer la explotación con cinco buques tripulados, cada uno, por treinta a treinta i cinco individuos. De estos buques tres se encuentran en Valparaíso i dos en Talcahuano. En este puerto i en Lebu, pescadores con botes i aparejos listos para la caza de la ballena. Las especies que beneficia esta compañía son las conocidas con el nombre de ballenas de esperma (cachalote) i algunas ballenas de las especies negras [...]. Esta pesca se verifica en las costas de Chile desde el mes de septiembre hasta el de abril.

[...]

[Se entiende por pesca de altura] la explotación en grande escala, i fuera de las costas habitadas o sujetas a dominio particular, que se hace de esta industria i para cuya ejecución se requieren grandes armamentos i que necesita de verdaderas navegaciones, i que impone por tanto a los muchos pescadores que en ella se ocupan la obligación de permanecer lejos de sus hogares largo tiempo, o sea el necesario para verificar la explotación en el lugar elegido. Esta clase de pesca puede comprender también la costera o puede solo verificarse en alta mar (Puga, 1885, p. 367).

En 1883 los cinco buques llevaron a Valparaíso 33 mil galones de aceite de esperma y 110 mil galones de aceite de ballena, y los botes pescadores de la costa 
enviaron 10 mil galones de aceite de ballena, con un total de 153 mil galones (Puga 1885, pp. 367-368). Estas cifras muestran que la producción de la caza costera es menos del $10 \%$ que la producción de la caza pelágica.

La diferencia fundamental entre ambos modelos de caza tiene que ver con su expresión en una porción de espacio/tiempo muy definida, donde las dinámicas sociales de la actividad se manifiestan y también en la cantidad de tripulantes y no tripulantes que participan.

En el caso de la caza pelágica esa porción de espacio/ tiempo está representada por el barco, un ámbito cerrado en el que convive diariamente una tripulación de entre 30 y 40 hombres, por un tiempo no menor a seis meses, llegando, a veces, a superar el ańo. Los botes balleneros se constituyen en "partes", componentes del velero, que actúan en forma colaborativa. En el barco también se procesa la ballena, de modo que la vinculación que existe en la caza pelágica con los espacios costeros es muy superficial. La ballena solo es vista por los hombres que trabajan en el velero. Los hombres que quedan en tierra únicamente tienen la posibilidad de ver la ballena transformada en aceite, no la ballena en su naturalidad y monumentalidad.

En cambio, en la caza costera, el espacio por excelencia es el bote, en el que trabajan seis tripulantes, que se vincula con otros botes, llegando hasta cuatro o seis en algunas ocasiones, para desarrollar algunas tareas cooperativas. La ballena se procesa directamente en la playa o en instalaciones costeras muy precarias, generándose un ámbito en el que participan también aquellos hombres que se quedan en la costa, los que se encuentran en una situación particular, pues también pueden ver la ballena y contemplar/participar en el proceso de transformación de la ballena en aceite.

Sin embargo, en muchos momentos, estos modelos se conectan e interrelacionan. La dinámica que genera la imbricación de ambos modelos se refleja en la información que hemos logrado rescatar sobre las actividades de Silverio Olate Olivares, experimentado ballenero de Tumbes, que llegó a ser en 1914 segundo piloto de la barca Josephine, de la Compañía
Chilena de Balleneros de Valparaíso y luego primer piloto de la fragata ballenera James Arnold, de Talcahuano, entre 1921 y 1922 . Otro caso es el de Nicolás Bécar Andariena, "famoso" pescador de Tumbes, que estuvo embarcado en el James Arnold, de Toro \& Martínez, cazando ballenas en Ecuador y luego se dedicó a organizar capturas "con anteojos de larga vista y banderolas desde la playa de Tumbes" cuando los cetáceos entraban en la bahía de Talcahuano (Fernández, 1964, p. 36). El oficio de cazar ballenas se aprende embarcado y luego se transmite en tierra, entre familiares y amistades. Seguramente hay muchos otros casos de los que no tenemos indicios.

\section{Continuidades y transformaciones}

La caza costera de ballenas en "aguas chilenas" es producto, por una parte, de la influencia norteamericana y por la otra, de la tradición de faenar ballenas varadas, presente en las costas chilenas incluso desde antes de la llegada de los europeos. En el lenguaje técnico asociado a la caza y al procesamiento de las ballenas se puede apreciar con mucha claridad la influencia estadounidense. Los nombres de las ballenas eran en su mayoría de origen inglés (Castillo, 1906 , p. 3). La ballena franca era conocida con el nombre de raituel (del inglés right whale), la ballena jorobada era denominada como ambaqui (bumpback whale), la orca era la ballena quila (killer whale), el cachalote el espamuel (sperm whale), la ballena de aleta era la finbaqui (fin whale), la ballena boba o ceibal (sei whale) y la azul era la alfaguara (blue whale). Además, varias de las herramientas utilizadas por los balleneros eran derivaciones de su nombre en inglés (Hernández, 1998). Por ejemplo, los cuchillos usados para obtener los trozos de tocino eran los espeles (del inglés spade) y un arma de fuego que disparaba arpones era el dátingan (de darting gun). Probablemente se usaron otros términos que no fueron registrados ni se los recuerda en la actualidad.

El caso brasileño ofrece ejemplos interesantes. Los vascos solo permanecieron diez ańos en el Brasil (1602-1612), pero las operaciones balleneras se mantuvieron hasta 1973, es decir, un grupo de brasileños, muchos de ellos esclavos, aprendió las técnicas y supo transmitirlas a través de sucesivas generaciones, por más de 350 años. 
También es importante el aprendizaje del oficio, no solo del cazador de ballenas o el descuartizador que trabaja en el procesamiento en las plantas, oficios que pueden aprenderse a bordo de los veleros, sino también la construcción de embarcaciones y de herramientas para el oficio. Se comienzan a construir chalupas balleneras en la zona de Talcahuano en la segunda mitad del siglo XIX. En 1870 se indica que hay una persona, de nacionalidad estadounidense, "especial para la construcción de chalupas expresamente para la pesca de ballenas, hombre mui perito e inteligente en dicha construcción". Ese año, Jorge Bealey "ha construido ocho y reparado cinco". El oficio es aprendido por chilenos y tenemos registros de carpinteros de ribera, en Tumbes y en la isla Santa María, construyendo chalupas a fines del siglo XIX para "la pesca de la ballena", como Alberto Monsalve, de Puerto Sur, en isla Santa María. Las chalupas balleneras se hacían en Tumbes, en algunos lugares de la costa del golfo de Arauco y en la isla Santa María, "en base a plantillas de manufactura inglesa o norteamericana que se encargaban, al igual que los implementos que se empleaban en la caza $[. .$.$] a los veleros balleneros que llegaban hasta$ nuestras aguas" (Fernández, 1964, p. 38). Los arpones, las lanzas, los "espeles" y otras herramientas de fierro eran elaborados por Abraham Velozo, en Talcahuano, utilizando también como modelo las piezas obtenidas de los veleros balleneros que recalaban en dicho puerto.

Otro punto de interés que podemos mencionar es el paso de la caza tradicional de ballenas a la caza moderna en una misma empresa ballenera. En 1932 la sociedad Juan Macaya e Hijos, una de las sociedades balleneras tradicionales más conocida, que operaba desde la isla Santa María, adopta buques a motor para remolcar tanto las chalupas cazadores como las ballenas cazadas. Sin embargo, la caza propiamente tal era todavía realizada con chalupas y arpones manuales. Pero en 1950 la empresa, con la denominación de Macaya Hermanos, se traslada al continente, levanta la planta ballenera de Chome, cerca de Talcahuano, y adopta la tecnología de la caza moderna comprando un buque cazador a la Compañía Industrial S.A., la INDUS (Quiroz, 2012).

\section{Conclusiones}

Con este estudio se ha logrado mejorar el conocimiento que se tenía de las operaciones balleneras tradicionales en las costas sudamericanas. Además de las operaciones costeras identificadas por Reeves y Smith en Brasil y Chile, hemos podido agregar las actividades balleneras de la Real Compañía Marítima en Uruguay y Argentina a fines del siglo XVIII y las operaciones pelágicas chilenas entre 1819 y 1922, primero ocasionales y luego periódicas. También sabemos que desde Perú se estaban desarrollando en el siglo XIX operaciones tanto pelágicas como costeras, aunque la información sobre ellas es todavía muy fragmentaria. Por el momento las hemos agrupado con las operaciones chilenas, sin distinguirlas, en espera de nuevas investigaciones. La información que tenemos nos indica que no había mayores diferencias entre ambas operaciones excepto su volumen, mucho mayor en el caso chileno que en el peruano, lugar donde no habría mayor interés en su desarrollo.

Podemos señalar que en la costa atlántica predomina la tradición ballenera vasca, que se mantiene y expande mediante la adaptación que realizan de ella colonos portugueses y esclavos africanos; mientras que en la costa pacífica es la tradición yanqui la hegemónica, que se manifiesta en dos modalidades, costera y pelágica, resultado de las adaptaciones realizadas por empresarios y pescadores chilenos y peruanos.

Se han detectado similitudes tecnológicas notables entre las operaciones costeras brasileñas y chilenas y también diferencias bastante significativas, sobre todo relacionadas con las formas de organización de las operaciones balleneras: concesiones del Estado en el caso brasileño y emprendimientos privados en el caso chileno. Esta es una línea de investigación que se mantiene abierta. ¿¿De qué manera las distintas tradiciones que operan, en el Atlántico la vasca y en el Pacífico la yanqui, son responsables de las diferencias que se pueden observar en las operaciones locales? ¿Por qué la tradición yanqui no tuvo mayor influencia en las operaciones brasileñas, a pesar de que cazaron ballenas por casi un siglo frente a sus costas? Se trata de temas que deben seguir investigándose, reuniendo información proveniente también 
de archivos norteamericanos -no solo brasileños y portugueses- que no han sido revisados con este propósito.

Es necesario, además, continuar con este ejercicio comparativo, ahora enfocándose en las operaciones balleneras modernas, presentes en Brasil, Argentina, Chile y Perú, con una fuerte influencia de las tradiciones noruega y japonesa.

\section{Agradecimientos}

Este trabajo fue escrito gracias al financiamiento otorgado al Proyecto 1170318 "Narrativas etnográficas y operaciones balleneras en las costas sudamericanas entre los siglos XVII y XX: patrones, transformaciones y continuidades" por el Fondo de Desarrollo Científico y Tecnológico (FONDECYT). Mis agradecimientos a los evaluadores de una primera versión del artículo que permitieron mejorarla sustancialmente.

\section{Referencias citadas}

Aguilar, A. (1986). A Review of Old Basque Whaling and its Effect on the Right Whales (Eubalaena glacialis) of the North Atlantic. Report of International Whaling Commission, Special Issue, 10, 191-199.

Aguilar, A. (2013). Chimán. La pesca ballenera moderna en la provincia ibérica. Barcelona: Universitat de Barcelona.

Basberg, B. (1998). The floating factory: dominant designs and technological development of twentieth century whaling factory ships. The Northern Mariner, 8(1), 21-37.

Basberg, B. (2004). The shore whaling stations at South Georgia: a study in Antarctic industrial archaeology. Oslo: Novus Forlag.

Bezerra, A. S. (2015). Arquivo e memória oral na produção de uma 'etnografia retrospectiva'. ANTROPOlógicas, 13, 67-78.

Brown, S. G. (1976). Modern whaling in Britain and the north-east Atlantic Ocean. Mammal Review, 6(1), 25-36.

Cartes, A. (2009). Los cazadores de Mocha Dick. Balleneros chilenos y norteamericanos en el sur del océano de Chile. Santiago: Pehuén.
Castellucci Junior, W. (2009). Caçadores de baleia: armaçōes, arpoadores, atravessadores e outros sujeitos envolvidos nos negócios do cetáceo no Brasil. São Paulo: Annablume.

Castillo, L. (1906). La pesca de la ballena en la isla Santa María. Santiago: Cervantes.

Cavieres, E. (1999). Comercio chileno y comerciantes ingleses, 1820-1880. Santiago: Universitaria.

Cédula de S. M. para el establecimiento de la Real Compañia Maritima (1789). Madrid: Imprenta Real.

Clapham, P. J. y Baker, C. S. (2009). Modern whaling. En Perrin, W. F., Würsig, B. y Thewissen, J. G. M. (Eds.). Encyclopedia of Marine Mammals (pp. 1239-1243). New York: Academic Press.

Coker, R. (1908). Las ballenas del Perú. Boletín del Ministerio de Fomento, VI (5),115-125.

Davis, L. E., Gallman, R. E. y Gleiter, K. (1997). In pursuit of Leviathan: technology, institutions, productivity and profits in american whaling, 1816-1906. Chicago, IL: The University of Chicago Press.

Denegri, F. (1997). Historia Maritima del Perú, La República: 1826 a1851. Conflicto Peruano-Ecuatoriano 1858-1859. Tomo VI, volumen 2. Lima: Instituto de Estudios Histórico-Marítimos del Perú.

Dolin, E. J. (2007). Leviathan. The history of whaling in America. New York: W.W. Norton \& Co.

Donovan, G. P. (1982). The International Whaling Commission and Aboriginal Subsistence Whaling: April 1979 to July 1981. Report of the International Whaling Commission, 4, 79-86.

Driessen, H. G. G. M. (2013). Suspense in Retrospective Ethnography. En Pelkmans, M. E. (Ed.). Ethnographies of Doubt: Faith and Uncertainty in Contemporary Society (pp. 149-164). Londres: I. B. Tauris.

Du Pasquier, T. (2000). Les baleiniers basques. París: Editions S.P.M.

Dublé Urrutia, D. (1905, febrero 7). Tumbes (V). La caza de la ballena. El Sur [Concepción], pp. 1, 5 .

Edmundson, W. y Hart, I. (2014). A história da caça das baleias no Brasil: do peixe real a iguaria japonesa. São Paulo: DISAL. 
Ellis, M. (1969). A baleia no Brasil colonial. Sao Paulo: Melhoramentos.

Ellis, R. (2009). Traditional whaling. En Perrin, W. F., Würsig, B. y Thewissen , J. G. M. (Eds.). Encyclopedia of Marine Mammals (pp. 1243-1254). New York: Academic Press.

El Mercurio de Valparaíso, 1871 (diciembre 14).

El Mercurio de Valparaiso, 1872 (julio 6).

Fernández, A. (1964). La caleta y su gente: Tumbes, estudio etnográfico (Memoria para optar al título de Profesor de Estado). Universidad de Concepción, Concepción.

Flores, R. (2010). Los balleneros anglo-norteamericanos y la apertura comercial del Pacífico sur a fines de la época colonial (1790-1820). Historia, XXXIV(2), 63-98.

Flores, R. (2011). Los balleneros anglo-estadounidenses y la cuestión de la 'extranjerización' del comercio peruano a fines de la época colonial, 1790-1820. América Latina en la Historia Económica, 36, 39-64.

Freeman, M. M. R. (1993). The International Whaling Commission, Small-Type Whaling, and Coming to Terms with Subsistence. Human Organization, 52(3), 243-25.

Gil, G. (2010). Etnografía, archivos y expertos. Apuntes para un estudio antropológico del pasado reciente. Revista Colombiana de Antropología, 46(2), 249-278.

Gonçalvez, R. De Sá (2009). Sociabilidades urbanas: cronistas e ranchos carnavalescos no Rio de Janeiro. En Gonçalves, J. R. S. y De C. Cavalcanti, M. L. V. (Eds.). As festas e os dias: ritos e sociabilidades festivas (pp.77-93). Rio de Janeiro: Contracapa.

Hacquebord, L. (2003). English and Dutch Whaling Trade and Whaling Stations in Spitsbergen (Svalvard) before 1660. International Journal of Maritime History, 15, 117134.

Hacquebord, L. (2010). English and Dutch whaling stations in Spitsbergen (Svalbard) in the $17^{\text {th }}$ Century. En Ringstad , J. E. (Ed.). Whaling and History III (pp. 5968). Sandefjord: Kommandør Chr. Christensens Hvalfangst Museum.

Harvey, D. (2014). Seventeen Contradictions and the end of Capitalism. Londres: Profile Books.
Heazle, M. (2006). Scientific Uncertainty and the Politics of Whaling. Seattle: University of Washington Press.

Hernández, J. (1998). Dónde viven las ballenas. Actividades balleneras en la isla Santa Maria y Chome del pionero Juan Macaya Aravena. Concepción: Aníbal Pinto.

Higham, J. E. S. y Neves, K. (2015). Whales, tourism and manifold capitalist fixes: New relationships with the driving force of capitalism. En Markwell, K. (Ed.). Tourism and Animals: Understanding Diverse Relationships (pp. 109-126). Bristol: Channel View Publications.

Kalland, A. y Moeran B. (1992). Japanese whaling: end of an era? London: Curzon Press.

Kasuya, T. (2009). Japanese whaling. En Perrin, W. F., Würsig, B. y Thewissen, J. G. M. (Eds.). Encyclopedia of Marine Mammals (pp. 643-649). Nueva York: Academic Press.

La Tarántula. Concepción, 1869 (marzo 1).

Lennartsson, R. (2011). Notes on 'not being there'. Ethnographic Excursions in Eighteenth-Century Stockholm. Ethnologia Europea, 41(1), 105-116.

Lindquist, O. (1994). Whales, dolphins and porpoises in the economy and culture of peasant fishermen in Norway, Orkney, Shetland, Faroe Islands and Iceland, ca. 900-1900 A.D., and Norse Greenland, ca.1000-1500 A. D. (Thesis for the Degree of Doctor of Philosophy). Saint Andrews, University of St Andrews, Escocia.

Lofstrom, W. L. (1996). Paita, Outpost of Empire. Mystic: Mystic Seaport Museum.

Marcus, G. (2001). Etnografía en/del sistema mundo. El surgimiento de la etnografía multilocal. Alteridades, 11, 111-127.

Martínez Shaw, C. (2008). Economía e imperio. Los establecimientos de la Real Compañía Marítima en América. Anuario de Estudios Atlánticos, 54(1), 593-630.

Melo, R. (1915). Historia de la Marina del Perú, III (Navegación Fluvial). Boletín de la Sociedad Geográfica de Lima, XXXI(I), 51-74.

Meseldzic, Z. (1985). Yugoslavos en el Perú. Lima: La Equidad. 
Moeran, B. (1992). The Cultural Construction of Value, 'Subsistence', 'Commercial' and Other Terms in the Debate about Whaling. Maritime Anthropological Studies, 5(2), 1-15.

Montalbán, C. y Capdevila, R. (2013). Los puertos del Plata en la ruta antártica durante la "época heroica”. Boletín del Centro Naval (Montevideo), 835, 99-110.

Montiel, F. (2010). Chiloé, historias de viajeros. Castro: Masterprint.

Palacio Rodríguez, R. (1991). Historia Maritima del Perú La República: 1884 a 1906. Tomo XII, volumen 2. Lima: Instituto de Estudios Histórico-Marítimos del Perú.

Pereira Salas, E. (1971). Los primeros contactos entre Chile y los Estados Unidos, 1778-1809. Santiago: Andrés Bello.

Pozzi, C. (1875). Memoria del Gobernador Marítimo de Talcahuano. En Memoria que el Ministerio de Marina presenta al Congreso Nacional (pp. 269-282). Santiago: Imprenta Nacional.

Proulx, J. P. (1986). Whaling in the North Atlantic from Earliest Times to the Mid-19 ${ }^{\text {th }}$ Century. Ottawa: National Historic Parks and Sites Branch Parks Canada.

Puga, J. (1885). De la pesca i de la caza en Chile. Boletín de la Sociedad de Fomento Fabril, 2, 365-381.

Quiroz, D. (2012). Cazadores tradicionales de ballenas en las costas de Chile (1850-1950). Santiago: Centro de Documentación de Bienes Patrimoniales.

Quiroz, D. (2015). Balleneros en la niebla: una mirada para-etnográfica de la caza de ballenas en Chile. Chungara. Revista de Antropología Chilena, 47(2), 319-330.

Quiroz, D. (2016). Excursiones etnográficas entre los pescadores de ballenas de Tumbes y la isla Santa María, Chile, a comienzos del siglo XX. Antropologias del Sur, 5, 103-123.

Reeves, R. R. (2002). The origins and character of 'aboriginal subsistence' whaling: a global review. Mammal Review, 32(2), 71-106.

Reeves, R. R. y Smith, T. D. (2006). A Taxonomy of World Whaling: Operations, Eras, and Data Sources. En Estes, J. A., DeMaster, D. P., Doak, D. F., Williams, T. M. y Brownell Jr., R. L. (Eds.). Whales, Whaling and Ecosystems (pp. 82-101). Berkeley: University of California Press.
Robbins, J. S. (1996). How Capitalism Saved the Whales. En Folson, C. W. (Ed.). The Industrial Revolution and the Free Trade (pp. 75-79). Irvington, NY: The Foundation for Economic Education Inc.

Sandoval, A. (1978). Talcahuano y los últimos balleneros a vela. Revista de Marina, 89(3), 233-235.

Shoemaker, N. (2014). Living with whales. Amherst, MA: University of Massachusetts Press.

Schokkenbroek, J. (2008). Trying-out. An anatomy of Dutch whaling and sealing in the nineteenth century, 1815-1885. Amsterdam: Aksant.

Silva, H. (1978). La economía pesquera en el Virreinato del Río de la Plata. Buenos Aires: Fundación para la Educación de la Ciencia y la Cultura.

Smith, T. D., Reeves, R. R., Josephson, E. A. y Lund, J. N. (2012). Spatial and seasonal distribution of American whaling and whales in the age of sail. PLoS One, 7(4), e34905.

Sotomayor, R. (1854). Informe del Intendente de Concepción en contestación a la Circular del 6 de marzo de 1854. En Memoria del Ministerio de Marina (pp. 50-58). Santiago: Imprenta de Julio Belin.

Takahashi, J. (1998). English Dominance in Whaling Debates A Critical Analysis of Discourse at the International Whaling Commission. Japan Review, 10, 237-253.

Takahashi, J., Kalland, A., Moeran, B. y Bestor, T. C. (1989). Japanese Whaling Culture: Continuities and Diversities. Maritime Anthropological Studies, 2(2), 105-133.

Tato, S. (1985). Hogei no rekishi to shiryo [Historia y estadísticas balleneras]. Tōkyō: Suisansha.

Thomas, K. (2009). The Ends of Life. Oxford: Oxford University Press.

Tilly, C. (1978). Anthropology, History and the 'Annales'. Review, 1(3/4), 207-213.

Tønnesen, J. N. y Johnsen, A. O. (1982). The History of Modern Whaling. Berkeley and Los Angeles, CA: University of California Press.

Van Ginkel, R. (2007). Coastal Cultures: An Anthropology of Fishing and Whaling Traditions. Apeldoorn: Het Spinhuis.

(c) (1) Este es un artículo de acceso abierto bajo licencia Creative Commons Reconocimiento 4.0 Internacional 